\title{
Electrophoretic deposition of colloidal crystals assisted by hydrodynamic flows
}

\author{
M. YOLDI, W. GONZÁLEZ-VIÑAS* \\ Department of Physics and Applied Mathematics. \\ E-mail: wens@fisica.unav.es \\ M. C. ARCOS, R. SIRERA \\ Department of Chemistry and Soil Science, Faculty of Science, University of Navarra, \\ c/lrunlarrea s/n 31080-Pamplona, Spain
}

Published online: 28 March 2006

\begin{abstract}
Latex-based colloidal crystals have been grown by electrophoretic deposition. The deposition has been assisted by hydrodynamic von Kármán-like flows, which lead to quantitative improvements. It has been studied the influence of applied voltage, deposition time and flow rate on the number of deposited layers and on the mean domain size. The samples were studied with microscopy and precision weight measurement. It has been found that there is a critical time after which the deposition mechanism changes, and the behavior of the system before and after this critical time is considered. The mean domain size and the deposition time were reduced to non-dimensional forms which show the collapse of the data for different applied voltages and flow rates into one curve. (c) 2006 Springer Science + Business Media, Inc.
\end{abstract}

\section{Introduction}

As an analogy to the ordered structures of atoms, colloidal crystals (CCs) are compact arrays of colloidal particles whose structures show periodicity in the length scale of the particles diameter. In one layer the colloids are ordered in a close packed arrangement, where each sphere touches six others, in order to minimize the interactions among the particles. These close packed layers stack themselves to form a three dimensional colloidal crystal $[1,2,3]$.

In the last decades, several techniques of arrangement have been used to prepare colloidal crystals. Gravitational sedimentation [4, 5, 6], electrostatic immobilization [7], colloidal crystal templating [8], vertical deposition [9, $10,11]$, shear alignment [12], oscillatory shear [13] or electrophoresis $[14,15,16,17]$ are some examples. The techniques which lead to more perfect structures base their success on the fact of having more than one privileged direction. The primary direction is perpendicular to the substrate, while the secondary ones promote the ordered arrangement of the colloidal particles.

In this paper, a novel method of arrangement is studied, which not only reduces the formation of defects but also decreases the time of deposition. The technique consists on an electrophoretic deposition assisted by hydrodynamic von Kármán-like flows [18]. The von Kármán flow is the one induced by an infinite rotating disk, where the fluid far from the disk is not moving. This kind of flow was generalized to the one induced by two disks, one rotating and the other at rest, which consists on having the fluid inside the system rotating with constant angular velocity and having boundary layers on both disks. This is resembling the case of the flow we are inducing with our experimental set up, which enters to the general denomination of von Kármán-like flow.

Colloidal crystals could be used as templates to prepare photonic crystals $[19,20,21,22,23,24,25]$, as well as to make efficient filtration membranes, new sensors [26] among other devices $[20,27,28]$.

\section{Experimental section}

2.1. Substrates and material

Aqueous dispersions of monodisperse polystyrene (mass/volume fraction of 10\%) latex spheres of $(975 \pm 10) \mathrm{nm}$ diameter, with a surface charge density of $(18.2 \pm 0.3) \mu \mathrm{C} / \mathrm{cm}^{2}$ due to sulphate groups were provided by Ikerlat Polymers. Aqueous ammonium hydroxide $(25 \% \mathrm{~V} / \mathrm{V})$ was provided by Panreac and absolute ethanol $(99.5 \% \mathrm{~V} / \mathrm{V})$ by Oppac. Ultra pure water, with a $15.2 \mathrm{k} \Omega \cdot \mathrm{m}$ resistivity, was obtained from a Mili-Q

*Author to whom all correspondence should be addressed. 


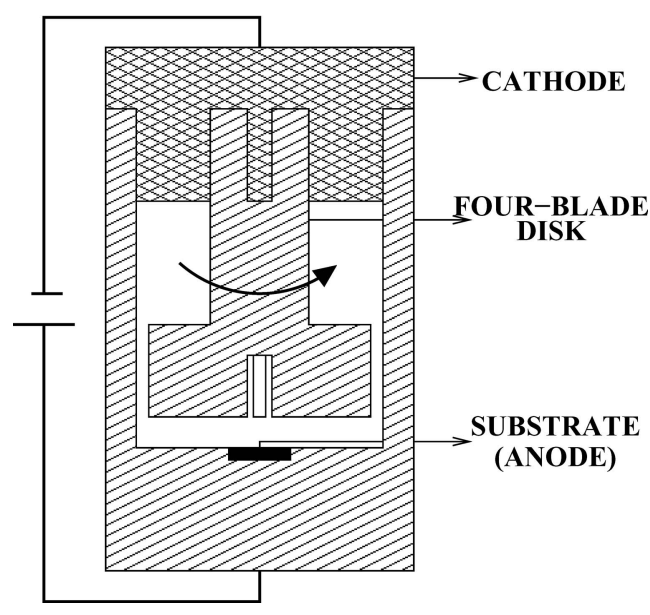

Figure 1 Deposition cell sketch.

water system. The substrates were $5 \times 5 \mathrm{~mm}$ glass slides with an Indium Tin Oxide (ITO) coating provided by VisionTek Systems Ltd.

\subsection{Experimental system}

The colloidal crystals were prepared in the deposition cell shown in Fig. 1. All electric connections were made of stainless steel, including the cathode itself. The hydrodynamic von Kármán-like flows were generated by rotating a four-blade disk [18]. Then, we can express the rate of flow in terms of the disk angular velocity of rotation.

Once the cell was filled with the colloidal dispersion, voltage is applied by a DC power supply to generate the electric field required to make the electrophoretic deposition. Once the crystals were prepared, digital images were obtained with a CCD camera coupled to an optical microscope Olympus BX50 at 400 magnifying power. By image analysis long-range order and defects were studied. More detailed information was obtained from Scanning Electron Microscopy (SEM) using a microscope Zeiss DSM 940.

In order to determine the number of deposited layers, the samples were weighed with a Mettler Toledo TGA/SDTA $851^{e}$ balance. The weight of a monolayer was calculated theoretically $(0.017 \mathrm{mg})$ and, in a previous study, weights of 8 reference depositions were measured. In this way, it is possible to obtain the theoretical number of deposited layers. The number of deposited layers also was measured from cross-section SEM micrographs. The agreement of the theoretical and measured values confirmed that the colloidal crystal weight is proportional to the number of layers deposited.

\subsection{Electrophoretic deposition}

Electrophoretic deposition of polystyrene latex spheres (PS) from the colloidal dispersion has been made in an aqueous-ethanolic medium (2:1 ethanol/water) with
$\mathrm{pH}=10$, adjusted by adding aqueous ammonium hydroxide, and a mass/volume fraction of PS of $0.33 \%$ [14].

$50 \mathrm{~mL}$ of this mixture were introduced into the deposition cell and then the electric field was applied during the required time. When the colloidal crystal was formed, a higher voltage was applied during a shorter time $(25 \mathrm{~V}$, 5 minutes) to partially coagulate the colloidal crystal obtained. Thus, it is possible to isolate and characterize the crystal without destroying it.

In order to study different conditions, several experiments were made. First of all the influence of the applied voltage was studied. All samples were prepared after $4 \mathrm{~h}$ of deposition applying voltages ranged from $2 \mathrm{~V}$ to $10 \mathrm{~V}$.

The influence of the deposition time has been also studied. The samples were prepared under two constant applied voltages $(5 \mathrm{~V}$ and $10 \mathrm{~V})$ using deposition times between $4 \mathrm{~h}$ and $16 \mathrm{~h}$.

Each study includes three sets of experiments at $0 \mathrm{rpm}$, $0.5 \mathrm{rpm}$ and $1 \mathrm{rpm}$ flow rate, denoted as series A, B and $\mathrm{C}$, respectively.

The latex-based spheres used to grow up the colloidal crystal are highly negatively charged. Without applying electric field and at room temperature, natural sedimentation is avoided by electrostatic repulsion. However, when an electric field is applied to the colloidal dispersion, the particles move to the positive electrode accelerating the process of crystallization. As it has been already mentioned, after the colloidal crystallization, the coagulation of the colloidal crystal is carried out, in order to stabilize its structure. Applying a higher voltage during a shorter time makes the spheres closer than their van der Waals distance, which joins them permanently [29, 30, 31].

\section{Results and discussion}

\subsection{Applied voltage measurements}

Optical images and SEM micrographs of the samples top view show that the colloids are arranged in a close packed arrangement, where each sphere touches six others in one layer (see Fig. 2). This close packed arrangement is

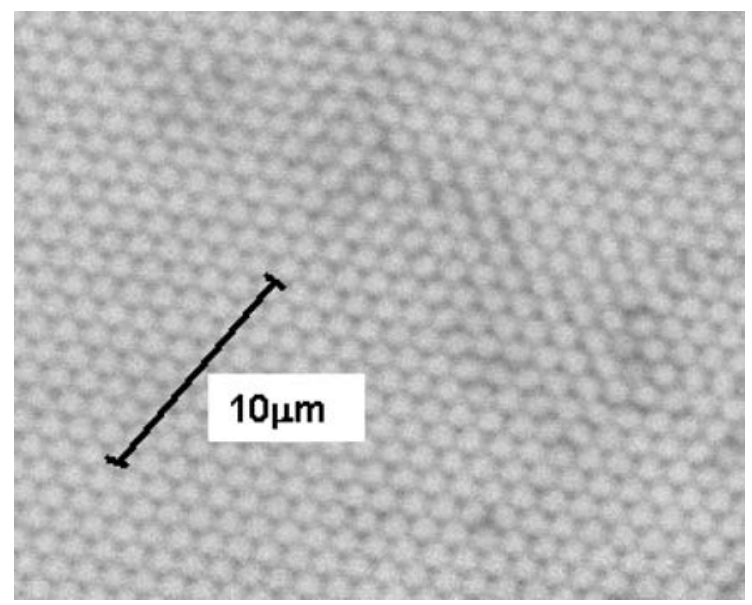

Figure 2 SEM micrograph of the top view of one of the samples. 
well-known in colloidal crystals [32, 33], since it minimizes the energy in the system. However, the determination of the samples crystalline structure is not the scope of this paper [34, 35].

Crystalline quality is one of the most important parameters to be considered, when using colloidal crystals in optical applications, since the presence of defects can have a huge influence on the diffraction properties. The linear long-range order in the upper layer of the samples is between 7 and 30 particles, depending on the experimental conditions.

Regarding the type of defects, while the number of colloidal particle vacancies and dislocations were negligible, planar defects perpendicular to the glass substrate were observed. They consisted on domain boundaries and cracks formed during the drying stage. Stacking faults (i.e. planar defects parallel to the substrate) were not considered in this study.

According to Petukhov et al. [36], the capillary forces generated during the drying process destroy the longrange order and break the crystal into smaller crystallites with slightly different orientations. Because of that, domains of higher size were expected in the wet colloidal crystals. As in many applications is not necessary to dry the colloidal crystal, it is very useful to consider the smaller crystallites forming one wet domain as the same domain. Thus, we will consider two adjacent crystallines as part of the same domain if their misorientation angle is smaller than $5^{\circ}$.

Besides, Jiang et al. [37] have published that the deposition of metal and the subsequent exposure of films to the high vacuum of the SEM damages the colloidal crystal structure and induces it to crack.

The size of the top layer of each domain was determined and an average size domain was calculated by image processing. Fig. 3 shows the average size of domains $(N)$ at different electric potentials and flow rates. All series show that the higher voltage is applied, the larger domains are obtained. Besides, at the same applied voltage, larger do-

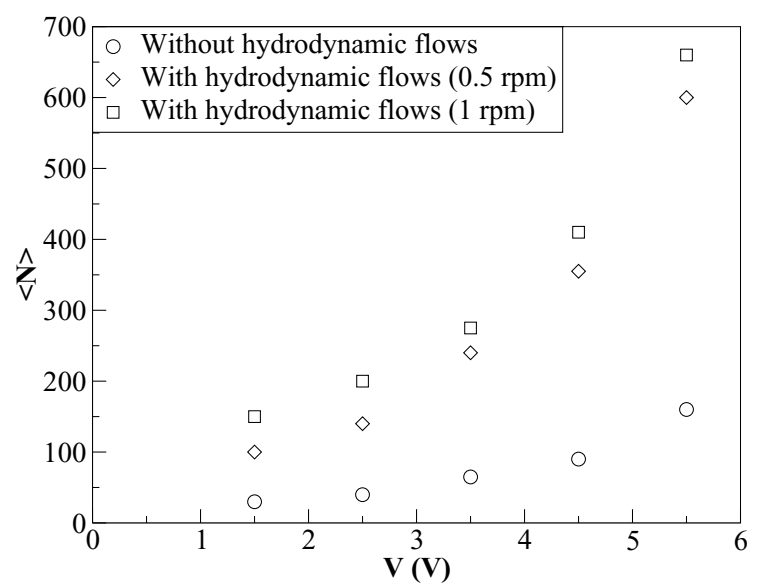

Figure 3 Average size of the domains of the top layer, (N), vs. applied voltage for a deposition time of $4 \mathrm{~h}$. mains were obtained at higher flow rates. Increasing either the applied voltage or the flow rate leads not only to larger domains but also to more regular ones. It seems that assisting the electrophoresis with hydrodynamic von Kármánlike flows leads to important quantitative improvements. Fig. 3 shows that the size of the domains increases up to five times at high voltages, when the results from series $\mathrm{A}(0 \mathrm{rpm})$ and $\mathrm{C}(1 \mathrm{rpm})$ are compared.

\subsection{Influence of the deposition time 3.2.1. Rate of deposition}

As it has been already mentioned, the number of layers was obtained from the weight of the samples. Figs 4 and 5 show the number of layers versus the time of deposition, at $5 \mathrm{~V}$ and $10 \mathrm{~V}$, respectively.

As it can be seen, the number of layers increases with the time of deposition, as expected, but with two different rates: the increase is very fast until a critical time, and then it becomes appreciably smaller. Besides, the critical time increases as the applied voltage does, $(10.5 \pm 0.6) \mathrm{h}$ for $5 \mathrm{~V}$ and $(12.0 \pm 0.5) \mathrm{h}$ for $10 \mathrm{~V}$.

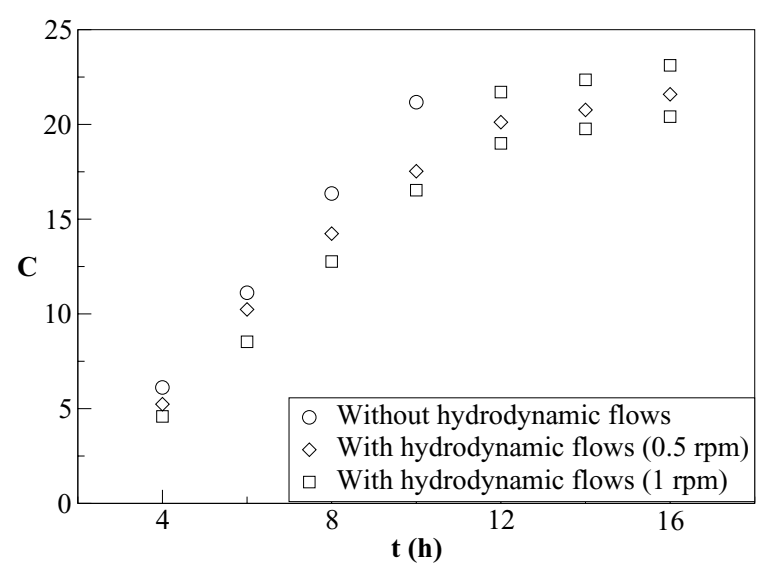

Figure 4 Number of deposited layers, C, vs. time of deposition at a voltage of $5 \mathrm{~V}$.

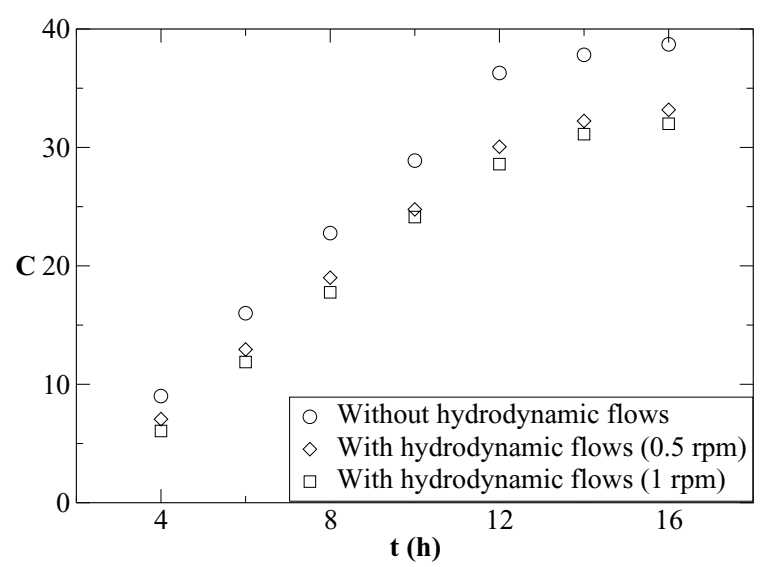

Figure 5 Number of deposited layers, C, vs. time of deposition at a voltage of $10 \mathrm{~V}$. 
Thus, there seems to be two different mechanisms in the electrophoretic deposition process. In the first one, the colloidal particles were quickly deposited on the substrate because they were repelled by the negative electrode and attracted by the positive one, i.e. the substrate. Both the anode attraction and the cathode repulsion accelerate the natural sedimentation of the colloidal particles. For higher times than the critical, the anodic forces are not strong enough to attract the particles in the solution due to the screening effects of the colloidal adlayers. From this time, the deposition results mainly from gravitational forces and from the repulsion caused to the colloidal particles by the negative electrode.

Moreover, at the same deposition time, the number of layers is smaller when the flow rate becomes higher. That means that assisting the electrophoresis with hydrodynamic von Kármán-like flows slows down the deposition process. The flow defines another privileged direction in the plane of deposition, and the particles move on the deposited surface to find a better site to lie. This makes the deposition process longer, and leads to more perfect colloidal crystals, reducing the number of defects.

\subsubsection{Size of the domains}

The effect of introducing von Kármán-like hydrodynamic flows in the deposition process on the size of domains has been studied. The results reveal how the average size of the domain is constant until a critical time, from which it starts to decrease. This critical time increases with the applied voltage, and its value is compatible with the critical time obtained in the previous subsection. This fact confirms the change in the mechanism of deposition, the first one governed by the electrophoretic forces and the second one by the gravitational ones. When a flow is applied and the deposition time is lower than the critical, there is a typical size of domain that increases with the flow rate, although it is nearly independent of the deposition time. This typical size of domain and the critical time have been used to obtain non-dimensional results. Fig. 6

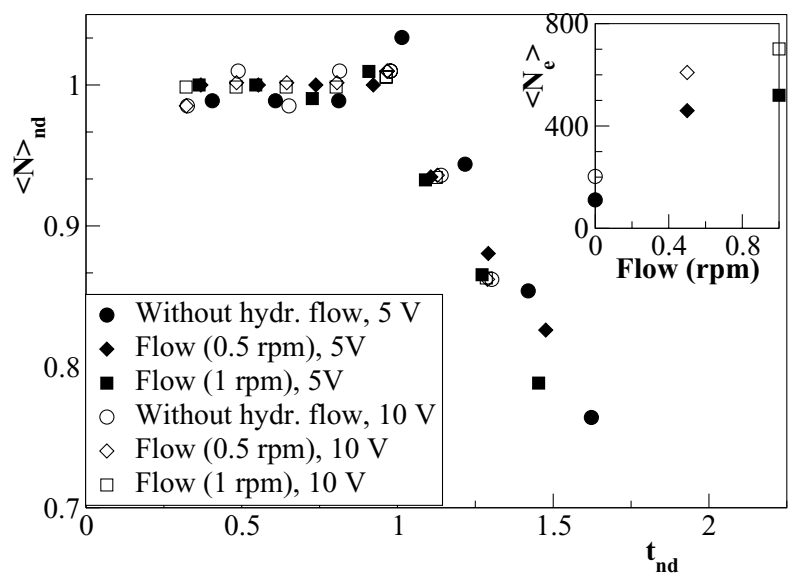

Figure 6 Non-dimensional average size of domain of the top layer, $\langle N\rangle_{\text {nd }}$, vs. non-dimensional time of deposition, $t_{\text {nd }}$. Inset: Average size of domains in the electrophoretic stage $\left\langle N_{e}\right\rangle$ vs. rate of flow (see text). shows that the reduced mean size of domains depending on the non-dimensional deposition time follows the same law regardless of the applied voltage and rate of flow, confirming the assumption of the different mechanisms in the deposition.

\section{Conclusions}

A novel method of electrophoretic colloidal crystallization assisted by von Kármán-like hydrodynamic flows has been studied. The experimental parameters were the deposition time, the rate of flow and the applied voltage.

Colloidal crystals with a thickness from 1 to 40 layers were deposited and have been found to consist of mono crystalline domains up to $10^{4} \mu \mathrm{m}^{2}$ in size. These domains exhibit a hexagonally close packing at the top layer. The main defects observed in the samples were grain boundaries and cracks formed in the drying stage.

It was proved that assisting the electrophoretic deposition by von Kármán-like hydrodynamic flows does not introduce qualitative changes in the process but leads to quantitative improvements such as a higher domain size and a smaller number of defects. The introduction of another privileged direction slows down the electrophoresis process. It has also been observed that the domain size, the order and the number of defects clearly depend on the applied voltage and the flow rate, and are independent of the deposition time. The electrophoretic deposition has a critical time, from which not only the rate of deposition slows down and becomes independent of the flow rate, but also the order decreases. This saturation time increases with the applied voltage, and reveals a change in the mechanism of the deposition. Moreover, the hydrodynamic flow slows down the electrophoretic deposition, which contributes to obtain more perfect colloidal crystals and a characteristic size of domain.

\section{Acknowledgments}

We acknowledge to J. Burguete and E. Görnitz for fruitful discussions. Also we are indebted for the viewing of samples by SEM to Prof. R. Jordana, and S. Olaizola. MY acknowledges to MECD scholarship and MCA to Gobierno de Navarra and to "Asociacion de Amigos de la Universidad de Navarra" scholarships. This work was partly supported by the Spanish MCyT (projects BFM2002-02011, MAT2003-02369) and PIUNA2003-34.

\section{References}

1. V. J. S ANDER S, Nature 24 (1964) 1151.

2. Idem. Acta Crystallogr. 24 (1968) 427.

3. Y. A. VLASOV, V. N. ASTRATOV, A. V. BARISHEV,A. A. KAPLYANSKII, O. Z. KARIMOV and M. F. LIMONOV, Phys. Rev. E61 (2000) 5784.

4. A. H. CARDOSO,C. A. P. Leite, M. R. D. ZANiQUElli and F. G ALEM B ECK, Colloids Surfaces A 144 (1998) 207.

5. F. KOPNOV, V. LISTSMAN and D. DAVIDOV, Synthetic Met. 137 (2003) 993. 
6. E. W. SEELIG, B. TANG, A. YAMILOV, H. CAO and R. P. H. CHANG, Mater. Chem. Phys. 80 (2003) 257.

7. K. S. MAYYA and M. SASTRY, Langmuir 15 (1995) 1902.

8. A. STEIN and R. C. SCHRÖDEN,Curr. Opin. Solid St.M. 5 (2001) 553.

9. L. M. Goldenberg, J. WAGner, J. Stumpe, B. R. PAULKE and E. GÖRNITZ, Mater. Sci. Eng. 22 (2000) 405.

10. Idem. Langmuir 18 (2002) 3319.

11. P. NOZAR, C. DiOnigi, A. Migliori, G. CALESTANi and L. CADEMARTIRI, Synthetic Met. 139 (2003) 667.

12. R. M. AMOS, J. G. RARITY,P. R. TAPSTER, T. J. SHEPERD and S. C. KITSON, Phys. Rev. E61 (2000) 2929.

13. O. Vickreva, O. KAlinina and E. KumACheVA, $A d v$. Mater. 12 (2000) 110.

14. A. L. ROGACH, N. A. KOTOV, D. S. KOKTYSH, J. W. OSTRANDER and G. A. RAGOISHA, Cham. Mater. 12 (2000) 2721.

15. J. P. HOOGENBOOM,A. YETHIRAJ, A. K. VAN LANGENSuURling, J. ROMiJn and A. VAN BlaAdern, Phys. Rev. Lett. 89 (25) (2002) 256104-1.

16. A. YethiRAJ, J. H. J. ThiJSSEN, A. WOUterse and A. VAN BLAADER N, Adv. Mater. 17 (7) (2004) 596.

17. W. D. RISTENPART, L. A. AKSAY and D. A. SAVILle, Phys. Rev. E69 (2004) 021405.

18. P. J. ZANDBERGEN and D. DIJKSTRA, Annu. Rev. Fluid Mech. 19 (1987) 465.

19. V. N. ASTRATOV, B. N. BOgOMOLOV, A. A. KAPLYANSKII, A. V. PROKOFIEV, L. A. SAMOILOVICH, S. M. SAMOILOVICH and Y. A. VLASOV, Nuovo Cimento Soc. ltd. Fis. D 17 (1995) 1349.

20. O. D. VELEV, T. A. JEDE, R. F. LOBO and A. M. LENHOFF, Nature 389 (1997) 447.

21. K. BUSCH and S. JOHN, Phys. Rev. E58 (1998) 3896.

22. A. A. ZAKHIDOV, R. H. BAUGHMAN, Z. IGBAL, C. GUI, I. KHAYRULlin, S. O. SANTAS, J. MARTI and V. G. RALCHENKO, Science 282 (1998) 897.
23. M. HOLGADO, F. GARCÍA-SANTAMARÍA, A. BLANCO, M. IBISATE, A. CIN-TAS, H. MÍGUEZ, C. J. SERNA, C. MOLPECERES, J. REQUENA, C. MIFSUD, F. MESSEGUER and C. LÓPEZ, Langmuir 15 (1999) 4701.

24. A. BLANCO, E. CHOMSKI, S. GRABTCHAK, M. IBISATE, S. JOHN, S. W. LEONARD, C. LÓPEZ, F. MESSEGUER, H. MíGUEZ, J. P. MONDIA, G. A. OZIN, O. TOADER and H. M. DRIEL, Nature 405 (2000) 437.

25. Y. A. VLASOV,X. Z. BO, J. C. STURM and D. J. NORRIS, Nature 414 (2001) 289.

26. V. L. ALEXEEV,S. DAS, D. N. FINEGOLD and S. A. ASHER, Clm. Chem. 50, 12 (2004) 2353.

27. O. D. VELEV, E. W. KALER and A. M. LENHOFF, Science 287 (2000) 2240.

28. O. D. VELEV and E. W. KALER, Adv. Mater. 12 (2000) 531.

29. M. TRAU, D. A. S AVILLE and I. A. A K S AY, Science 272 (1996) 706.

30. Idem Langmuir 13 (1997) 6375.

31. H. D. YARDS, J. NEWMAN and C. J. RADKE, Colloid Interf. Sci. 262 (2003) 442.

32. S. TSUNEKAWA, Y. A. BARNAKOV, V. V. POBORCHII, S. M. SAMOILOVICH, A. KASUYA and Y. NISHINA, Microporous Mater. 8 (1996) 275.

33. H. MígueZ, F. MESSEGuER, C. LóPEZ, A. MifSUd, J. S. MOYA and L. VÁZQUEZ, Langmuir 13 (1997) 6009.

34. A. VAN BLAADEREN, R. RUEL and P. WILTZIUS, Nature 385 (1997) 321.

35. A. D. BRUCE, N. B. WILdING and G. J. ACKLAND, Phys. Rev. Lett. 79 (1997) 3002.

36. A. V. PETUKHOV, I. P. DOLBNYA, D. G. A. L. AARTS and G. J. VROEGE, Phys. Rev. E69 (2004) 031405.

37. P. JIANG, J. F. BERTONE, K. S. HWANG and V. L. COLVIN, Chem. Mater. 11 (1999) 2132.

Received 26 May

and accepted 13 September 2005 